\title{
O TRABALHO LITERÁRIO PRESENTE NO POEMA MODERNISTA COBRA NORATO: UMA LEITURA DA TRADIÇÃO NA RUPTURA.
}

\section{THE LITERARY CRAFTSMANSHIP IN THE MODERNIST POEM COBRA NORATO: A READING ON TRADITION IN RUPTURE}

\author{
Recebido: 27/03/2020 | Aprovado: 25/05/2020 | Publicado: 10/07/2020 \\ DOI: https://doi.org/10.18817/rlj.v4i1.2162
}

Paula Rosa ${ }^{1}$

Orcid ID: https://orcid.org/0000-0002-7050-9211

\begin{abstract}
Resumo: Além de empenharem-se por uma autonomia cultural brasileira, é sabido que as obras nascidas sob a égide ideológica da Semana de 22 esforçaram-se em desprezar convictamente a tradição e os cânones formais. Cobra Norato, poema maior de Raul Bopp, publicado pela primeira vez em 1931, pretendeu confirmar tais premissas. Entretanto, no substrato do folclore amazônico que permeia esta poesia, podemos observar um trabalho literário que recupera metáforas e insumos clássicos. Solicitando a noção de pathosformel (Warburg, 2010), o presente artigo investiga como a linguagem poética de Cobra Norato (1931) repete magistralmente o imaginário mítico em sua macro e microestruturas, apontando para uma noção secular sobre arte - e por conseguinte sobre a Literatura - como artefato estético. Em paralelo a tal questão, este trabalho analisa como signos comuns à cultura clássica atravessam esta poesia de corrente modernista. Veremos assim, que o modo de refazer poeticamente o mito serpentário não se furtará ao diálogo com a antiguidade greco-latina, sugerindo a sobrevivência da tradição na ruptura.
\end{abstract}

Palavras-chave: Poesia. Pathosformel. Mito. Modernismo brasileiro. Tradição.

Abstract: Besides working towards a Brazilian cultural autonomy, literary works conceived under the ideological protection of the Brazilian Modern Art Week of 1922 made an effort to convincingly despise the tradition and formal canons. Cobra Norato, a major poem by Raul Bopp, first published in 1931, intended to confirm such premises. However, in the substrate of the Amazon folklore that permeates this poem, a literary craftsmanship which recovers metaphors and classical inputs can be perceived. As we bring into play the idea of pathosformel (Warburg, 2010), this paper investigates how the poetic language of Cobra Norato (1931) repeats majestically the mythical imaginary in its macro and micro structures, pointing towards a secular notion of art - and, thus, of literature - as an aesthetic artifact. At the same time, this paper analyses how the common signs of classical culture permeate this modernist poem. We shall see then that the craft of reconstructing poetically the serpentarium myth does not shy away from the dialogue with the Greco-Roman world, which suggests the survival of tradition in rupture.

Keyworkds: Poetry. Pathosformel. Myth. Brazilian Modernism. Tradition.

\section{Introdução}

"El arte convierte cada creatura en un Argo de mil ojos para que se vean

\footnotetext{
1 Professora de Língua Portuguesa, Língua Espanhola e respectivas Literaturas, no Instituto Federal de Educação do Rio de Janeiro (IFRJ). Mestra em Literatura Brasileira pela Universidade do Estado do Rio de Janeiro (UERJ). Graduada em Letras pela mesma universidade (UERJ), Email: paula02rosa@gmail.com
} 
el alma y la espiritualidad interior en todos los puntos" (HEGEL, In: SZONDI, 1992, p. 212). Por seus olhos, a alma da arte não apenas vê mas, principalmente, deixa ser vista. Afinal, os olhos são as janelas da alma, acrescenta Szondi. A metáfora utilizada por Hegel para pensar a arte clássica clarifica a qualidade que a obra tem de incorporar formal, material e plasticamente o seu conteúdo. Assim, sua superfície, seja ela material ou poético-linguística, deixa ver seu conteúdo do mesmo modo que este conteúdo se manifesta na sua arquitetura.

Toda obra de arte é um objeto técnico por excelência, exige um esforço mental por parte do artista, faz-se com trabalho e modelação. A teoria hegliana da poesia revela, entre outras coisas, que a competência da arte clássica está em dizer a verdade na forma adequada da verdade, os elementos que a constituem se ajustam perfeitamente a uma forma. $\mathrm{Na}$ arte clássica, pensava Hegel (In: SZONDI, 1992), o espírito encontra seu corpo, seu alinhamento harmônico.

Quando a verdade livre, que se autogerencia, encontra sua formalização perfeita, temos aí a delineação da estética. Assim a estética torna a ideia, ou a verdade livre, acessível à nossa contemplação, através da forma sensível. Essa verdade seria, portanto, o conjunto de ideias capazes de sustentar com força a relação entre o conceito e a forma de maneira fecunda. É aquilo que a arte trabalharia desde sua origem: as ideias apresentadas com uma elaboração rigorosa tecida fio a fio a partir de uma instrumentalidade conceitual riquíssima e integrada. Nesse sentido, desenvolve-se "uma configuração que 'fala' e que não deixa escapar nada à formulação discursiva dos níveis de constituição e de integração simbólica daquela arte." (HUCHET, In: DIDI-HUBERMAN, 1985, p.16). Esta verdade faz-se corpo atravessado de potencialidades expressivas que são configuradas no tecido do objeto artístico.

Desse modo, a criação artística colabora de maneira privilegiada com a elaboração das questões nela suscitadas. Convoca o material necessário à verossimilhança dos conteúdos ressaltados nas estruturas semiológicas e formais. A imagem da arte (neste caso, arte literária) é analisada como um corpo e um signo indissociavelmente envolvidos, de modo que a estética desempenha uma função tornada tátil. A estética será aquilo que sem a ideia, ou a verdade da obra [literária], não pode acontecer e ao mesmo tempo é o que constitui esta obra. O método se transforma em conteúdo na estética clássica e estes 
permanecem intimamente ligados: "O signo e o nome da divindade tem o mesmo tempo e o mesmo lugar de nascimento." (DERRIDA, 1973, p. 27)

Assim, entendemos que a arte, enquanto artifício e material técnico que é, lança mão de recursos para materializar as ideias nela contidas. Em Oréstia (ÉSQUILO, 2003) por exemplo, trilogia cujo tema é a maldição ancestral dos Atríadas, as histórias versadas por Ésquilo, ao serem poeticamente processadas, já não são mais o mito, mas sim obra de arte. Como arte, sua organização figural, poética e simbólica materializa a questão que está sendo trabalhada no enredo: as mudanças sociais do direito. Entendemos tal objeto como tangível de estética, verificando suas camadas de procedimento, analisando sua urdidura. Isso é o que se pretende fazer aqui, com o poema Cobra Norato (2009) de Raul Boop.

Por questões obvias, Cobra Norato (2009) não é uma arte clássica, tampouco se propõe a empreender uma experiência do clássico, como Ismene, princesa de Tebas (2013) de Pedro de Senna e a Trilogia Perversa (1988) de Ivo Bender - peças teatrais que, sob uma mirada contemporânea, jogam com os elementos do clássico. Entretanto, assim como em Oréstia (ÉSQUILO, 2003) e outras obras clássicas, aquilo que se diz em Cobra Norato está confirmado na maneira como é dito, ou seja, o poema deixa ver em todos os pontos da estrutura do discurso o tema que the serve de base: o retorno a uma dimensão primordial.

Fazendo uso de outros caminhos, seja pelo gênero épico, seja pelo tema mítico, vemos que o clássico também se manifesta em Cobra Norato, confirmando seu caráter de copiosa nascente onde artistas de distintas épocas e quadrantes garimpam inspirações. A épica de Cobra Norato, de fato, não imita as versões clássicas desse gênero já que, em sua mescla de procedimentos, auxilia na afirmação do novo, materializando uma épica moderna e Modernista. No entanto, os insumos clássicos funcionam como matérias que sobrevivem no contorno da obra, comprovando que o clássico não cessa de retornar espontânea ou compulsoriamente, mesmo que de forma traduzida ou transfigurada, como observaremos.

\section{Cobra Norato encontra sua pathosformel}

Aby Warburg (2010), defendendo a ideia das cadeias de transporte de 
imagens, entra no campo das metáforas em função do âmbito da pathosformel. $\mathrm{O}$ estudioso solicita a noção de pathosformel ao perceber, em algumas figuras e produções esculturais, gestos e expressões corporais que se propunham como manifestações de impulsos interiores. Warburg identifica nelas a plasmação física e material de algo abstrato, entendendo que o efeito criado na configuração da personagem é capaz de transportar o espectador aos sentimentos e simbolismos evocados pelos gestos.

Resgatando o icônico e o dêitico em certas atitudes picturais, o teórico concebe a pathosformel como representação densa de convenções e conteúdos afetivos ou psíquicos encrustados nos gestos. O conceito é assim transferido da palavra para a imagem. Com Aby Warburg aprendemos que tais formas têm um certo caráter antropológico, uma vez que remetem a uma memória corporal bastante arcaica, perdida com o decorrer do tempo, no entanto, cristalizada em gestos metafóricos. Uma forma de dizer antes que a palavra apareça.

Todavia, esta ideia pode ser transportada do código pictórico para o código verbal, poético. O literário também trabalha nesta área. É certo que com a literatura o caráter visual se diferencia: o espectador que via gestos icônicos nas artes plásticas e fotográficas, agora vê os gestos na retórica. Trata-se de uma outra forma de [re]produção e interpretação da imagem, um outro modo de fazer ver. O texto poético lapida em si sua musicalidade, sua sensibilidade tátil, seus simbolismos - a partir da própria estruturação, concepção arquitetônica e adaptação dos termos. Desse modo, a pathosformel está contida no verbal, nos inúmeros signos que, assim como nas figuras esculturais, vão dramatizando sentimentos e maximizando aquilo que está sendo representado.

\section{A repetição do imaginário mítico na poesia}

No que concerne a Cobra Norato (2009), poema de Raul Bopp que aqui nos importa analisar, observamos que o poeta realiza um esforço para adquirir um estilo em consonância com o mundo que pretende evocar pela poesia. $O$ artista tinha consciência de que existia um modo diferente de pôr-se diante da realidade, um modo em que a manifestação do mito era uma realidade espiritual. $O$ poeta entende que dessa perspectiva deveria brotar também uma linguagem nova. 
Assim, o que vemos em Cobra Norato (2009) é a busca de uma simbiose perfeita entre conteúdos e meios expressivos. É o mito que inventa sua própria a linguagem. É a floresta que dita o seu vocabulário e sua sintaxe. Aí está a pathosformel: a poesia, em todos os níveis, materializa as ideias que represa. Antes de analisar essas circunstâncias no poema, façamos uma breve apresentação do enredo da obra.

Em Cobra Norato (2009) - poema dividido em 33 breves cantos -, o personagem central, herói narrador, é um homem que se apossa da pele da Cobra e inicia sua trajetória. Este ser tem uma obsessão do tipo erótico-amorosa pela filha da rainha Luzia, a heroína, que Cobra Grande, o vilão, raptou e mantem sob seu poder. No percurso em busca de sua amada pelas terras do Sem-fim, Norato terá a ajuda de outros personagens fantásticos, como o compadre Tatu-debunda-seca, o Jabuti, o Pajé-pato...

Cobra Grande (Boiúna, Caboclo do Rio, Demônio d'água...) é uma espécie de ser maléfico arrasador de embarcações, raptor de donzelas, bastante recorrente nos causos narrados pelas comunidades ribeirinhas amazonenses.

Retirando sua inspiração do folclore popular da Cobra Grande, Raul Bopp também procura o herói de sua história no rico patrimônio mítico da selva tropical. Tal herói foi identificado na figura de Cobra Norato. Essa escolha não foi aleatória. O poeta afirma que escolhe este ser por sua dupla natureza: serpente e homem ao mesmo tempo. "Cobra Norato concentra em si a síntese do humano e do sobrenatural" (BOPP, 1997, p.59).

$\mathrm{Na}$ terra onde a serpente realiza sua viagem, animais, árvores, folhas, rios, e outros elementos do meio físico atuam como personagens de primeiro plano. O personagem central dialoga com os seres da natureza. Todos estão unidos por uma relação mágica:

Aqui é a escola das árvores

Estão estudando geometria

-Vocês são cegas de nascença Têm que obedecer ao rio

-Ai ai! Nós somos escravas do rio

Vocês estão condenadas a trabalhar para sempre sempre

Têm a obrigação de fazer folhas para cobrir a floresta

-Ai ai! Nós somos escravas do rio

(BOPP, 2009, p.10) 
Conforme afirma Ligia Averbuck (1985, p. 114), "no mundo primitivo, a 'magia' se afirma como força natural". Ao atribuir poderes especiais a todo o universo, isto é, aos seres humanos e não humanos, a concepção mágica do mundo participa da estrutura do poema e determina suas formas.

É exatamente a captura desse sentido de "espiritualização material" que o poema realiza em sua urdidura semântica e verbal. Ao procurar a representação de um mundo virgem, o poeta recria as formulações do pensar e do sentir primitivos, fazendo de Cobra Norato, em seu gesto de pathosformel, uma expressão coerente com os objetivos recriados: o mundo natural, a floresta mítica selvagem.

\author{
Vou furando paredões moles \\ Caio num fundo de floresta \\ inchada alarmada mal-assombrada \\ Ouvem-se apitos um bate-que-bate \\ Estão soldando serrando serrando \\ Parece que fabricam terra \\ Ué! estão mesmo fabricando terra \\ (BOPP, 2009, p.11)
}

A dramatização do acontecimento - através de uma transcrição dos movimentos, sons e cores que constituem paisagens e personagens - é uma das características mais marcantes da trama poética. "Justamente essa dramatização bou 'presentificação' de paisagens, cenas e ações é um dos principais atributos do mito popular" (ELIADE, 1985, p.40).

Também através do deslocamento dos nexos lógicos entre os termos, bem como pelas inusitadas adjetivações, são criadas relações insólitas dentro do poema Cobra Norato (2009), como estas a seguir: "árvores de galhos idiotas", "horizontes beiçudos", "mata-paus vou-bem-de-saúde", "música com gosto de lua”, "raízes com sono", "mar desarrumado", "mangue de cara feia".

Além disso, o léxico adotado no livro é de estilo cotidiano, popular, afetivo, próprio dos causos. Frases coordenativas, curtas e concisas, atributo igualmente comum às lendas, fábulas e aos vários tipos de contos orais estruturam a sintaxe: "acordo/ a lua nasceu com olheiras/ o silêncio dói dentro do mato" (BOPP, 2009, 
Ao logo do poema existem estrofes e os versos que são livres. Há ritmos que não obedecem a nenhum esquema fixo, sendo fragmentados, dinâmicos e seguindo a imposição do ambiente representado. Entretanto, em outros momentos, verificamos a predominância de versos que se organizam em estruturas bem definidas, como em redondilha maior, por exemplo, versos de sete sílabas poéticas. Esse era um recurso muito recorrente no Trovadorismo, para a produção das Cantigas Medievais.

Nesse sentido, apesar de os modernistas investirem com frequência na liberdade dos versos, os diálogos com certas tradições são comuns no que concerne à estrutura de poemas. É o que verificaremos no canto $\mathrm{XXV}$, quando Cobra Norato transforma-se em trovador. Em fragmento do canto citado, ademais da repetição cadenciada do termo "Tajá", temos a utilização da redondilha para favorecer a noção de mundo que está sendo convocada. Assim, os versos estabelecem relações fônicas que reforçam o ritmo de encantamento, lembrando as fórmulas mágico-religiosas dos ritos aos quais os mitos se associam (AVERBUK, 1985, p. 143).

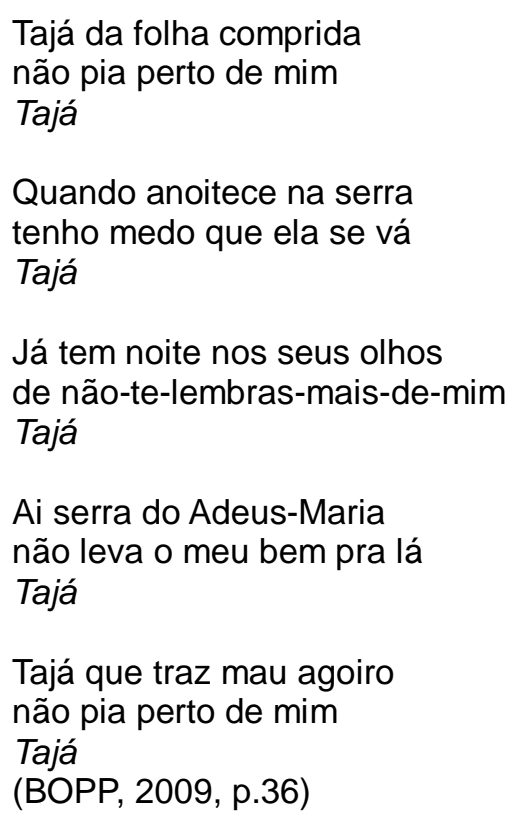

Cenários e ações de Norato, bem como dos outros personagens, não são apenas descritos, mas também "representados" na dinamicidade fonológica, 
morfossintática e semântica do poema. Se é verdade que no caso específico de Cobra Norato (2009) o mito está no cerne da poesia, já que participa de sua composição, fica fácil perceber que o poético se apropria das formas que este imaginário assume no contexto verbal.

\section{A metáfora boppiana}

"Em vez de 'falar' do mito, o poeta prefere traduzi-lo em uma linguagem que seja a mais próxima daquela mítica [...] Bopp assume a ótica do próprio mito" (OLIVEIRA, 2002, p. 284). A linguagem de Cobra Norato (2009) se realiza, assim, enquanto metáfora.

Uma das ideias fundamentais de Blumenbarg (1999) é a das metáforas absolutas. A metáfora absoluta substitui um conceito que não consegue ser dito de outra forma, auxiliando no campo daqueles princípios que são insubmissos a conceitualizações. Tirando proveito dessa noção, podemos dizer que, mesmo não tendo um caráter absoluto, a palavra poética boppiana trabalha no campo das metáforas, estabelecendo um corpo poético cuja interpretação não pretende deixar nada de fora do seu alcance totalizante, verbalizador e discursivo.

Assim, a figurabilidade do poema remete ao poder do onírico, a um espaço vegetal e selvagem na produção das imagens poéticas. Aquilo que se canta ao longo dos versos é como uma prática que não rompe com os postulados presentes na concepção da ideia. A linguagem operada em Cobra Norato (2009) propõe-se como ilustração, sem a qual o pensamento não absorveria a força dos conceitos ali circulados: a mímesis de um estado primevo, fantástico e "alucinatório".

A intuição de que era necessário criar uma poesia "à maneira da vida vegetal" (BOPP, 1977, P. 12) é chave de interpretação da linguagem surpreendente que Cobra Norato instaura. Vê-se aí uma poética expressiva de caráter animista, analógico, sinestésico, que em todos os âmbitos concorda para a materialização do extraordinário, típico da perspectiva arcana que não separa lógico e ilógico, racional e irracional.

O poema começa onde o mito termina. O que temos não é o mito, mas sim uma majestosa criação literária, um artefato. A poética boppiana realiza assim 
uma comunicação háptica, trabalhando com sucesso na criação dos efeitos que Ihe convêm. Afinal, instituir o nome de Deus, como diria Silviano Santiago (1978, p.15), equivale a impor um código linguístico no qual seu nome circule em perfeita transparência.

\title{
O clássico em Cobra Norato
}

É sabido que a literatura modernista brasileira, pensada sob os princípios da liberdade de criação e da revolução do verso, empenhou-se convictamente em desmobilizar os cânones formais. A incorporação do elemento popular, a desestabilização das categorias do gênero etc. não foram meros projetos da vanguarda de 22 , hoje eles fazem parte de suas maiores conquistas, integrandose ao modo de ser da literatura brasileira. Trata-se de uma rebeldia vitoriosa.

Assim, estabelecer critérios precisos para definir as obras modernistas torna-se uma tarefa dificílima. Como afirma Lígia Averbuck (1985, p. 95), "ao procurarem fixar de forma brasileira uma realidade 'brasileira' a maioria dessas obras, de certo modo, escapa aos critérios formais de que o crítico dispunha para interpretá-las."

\section{O problema da classificação do poema}

Cobra Norato (2009), como muitas outras criações modernistas, é um desses casos literários que desestabilizam os rigores classificatórios. Sustentado por um desenvolvimento discursivo que se propõe, em linhas gerais, como tipologia narrativa, o poema conta a história de um herói empenhado na conquista da filha da rainha Luzia. Incansável na busca de sua obsessão amorosa, Norato precisará enfrentar os desafios impostos pela floresta equatorial, vencer a Cobra Grande, mito serpentário amazônico, e superar os obstáculos que lhe serão impostos:

\author{
-Agora sim \\ vou ver a filha da rainha Luzia! \\ Mas antes tem que passar por sete portas \\ Ver sete mulheres brancas de ventres despovoados
}


guardadas por um jacaré.

-Eu só quero a filha da rainha Luzia.

Tem que entregar a sombra para o Bicho do Fundo

Tem que fazer mironga na lua nova

Tem que beber três gotas de sangue

(BOPP, 2009, p.5)

Numa leitura inicial, já se pode verificar nessa estrutura poética as formas da literatura épica, série que tem como essência a narrativa dos feitos de um herói, que precisa vencer obstáculos na luta pela conquista de seu ideal. Além disso, o fundo mítico e maravilhoso da obra reafirmam tal interpretação. No prefácio à sétima edição do poema, M. Cavalcante Proença considera que Cobra Norato é uma epopeia que narra os feitos de um novo Teseu (Norato) que enfrenta um minotauro indígena (Cobra Grande) em uma aventura cosmogônica (PROENÇA, In: BOPP, 1973, p. 12).

Sobre a origem da personagem, Raul Bopp tece comentários num artigo publicado em Porto Alegre, no ano de 1968: "Disseram-me que Curupuru no fundo da baia de Monguça era lugar por demais visajoso... Nos chamados 'portos de lagoa', podia-se ouvir muita coisa sobre o fabulário da região, numa mistura de mitos indígenas com elementos de procedência europeia." Assim também em Cobra Norato (2009) reconhecem-se tanto o substrato dos folclores amazônicos quanto a lenda do Minotauro que, de quando em quando, demanda uma donzela (BOPP, In: AVERBUCK, 1985, p.99).

Por outro lado, a atividade do narrador de Cobra Norato carrega consigo uma certa consciência crítica do fazer poético, atitude comum nas produções artístico-literárias a partir de fins do século XIX. Nas estrofes iniciais do primeiro canto do poema lemos: "- Quero contar-te uma história/ vamos passear naquelas ilhas decotadas/ Faz-de-conta que há luar" (BOPP, 2009, p.3). O narrador anuncia que vai contar uma história e este gesto ocorre pelo "faz-de-conta" que, além de ser um apelo ao lúdico, solicita ao leitor a suspensão da descrença.

O vigésimo verso, por sua vez ("- Então você tem que apagar os olhos primeiro"), funciona como uma advertência de que, para embarcar nessa viagem poética e fantástica que vai ser realizada, o leitor deve estar também ele disponível para a mudança radical de perspectiva. Assim, como podemos perceber, investe-se numa metalinguagem, ainda que de forma sutil. A referência 
ao interlocutor, mesmo que vedada, desautomatiza as formas da linguagem épica.

Há de se considerar também que a elaboração da matéria épica ganha um caudal lírico em Cobra Norato (2009). Diferente da atitude distanciada que se observa na epopeia em sua versão clássica, a presença de um "eu" autorreferenciado e do envolvimento emocional na aventura cantada remetem, de fato, às categorias do lírico. Sobre isso, acrescenta Averbuck (1985, p.98): "a expressão lírica do poema é revelada na expressão simbólica das imagens, nos elementos visionários da febre que move o herói, consubstanciada na perspectiva individual do ente que, enfiado na pele de seda da cobra, percebe insistentemente sua amada." No entanto, adverte: "o caráter fluido de que se reveste o poema advindo de seu fundo mítico, o aproxima simultaneamente do lírico - no que este gênero tem a ver com as categorias do imaginário - e do épico, cujo núcleo reside em sua natureza de relato, narrativa de uma história sagrada."

\section{A tradição transfigurada}

Cobra Norato (2009) propõe-se como texto moderno/modernista, narrando a participação do "eu" no percurso histórico dos tempos míticos da formação brasileira. A "contaminação" da configuração é uma das características da épica moderna. Sua nova concepção estrutural e temática desconcerta o leitor, posto que o significado irradia em várias direções onde, frequentemente, os parâmetros teóricos, abalados por um novo tempo, fazem pensar numa anormalidade da forma.

A esta renovação literária, Carlinda Nuñez (2011, p.33) chama de "épica rejuvenescida", deixando claro, a partir de tal designação, que apesar das revigorações empreendidas pela inventividade brasílica mais recente, o nicho clássico se mantem. Nesse sentido, a autora esclarece que esta "contaminação" da épica, de que viemos comentando, funciona como uma atualização do gênero, parte do jogo da tradução do clássico na América Latina.

Retomando Silviano Santiago (2002), podemos entender que o artista incorpora a tradição, enfrentando uma estética essencialmente clássica como a épica, através do suplemento, respaldando o pluralismo. O "retorno em diferença", ilustrado por Oswald de Andrade (2011) no Matriarcado de Pindorama, pode 
servir, portanto, de ilustração para aquilo que aqui se busca compreender, isto é, a contemporaneidade do passado, agora transfigurado.

A exploração dos temas clássicos e do imaginário greco-latino no panorama da literatura modernista brasileira realiza as experiências de sincretismo religioso e de simbiose étnica do país. No deslizamento de um estilo rejuvenescido, modernistas como Raul Bopp aproveitam a literatura de tema mítico como prerrogativa de afirmação da autonomia cultural brasileira.

Ainda no mesmo artigo, Nuñez pondera que o centramento na matéria mítica influi na dimensão temporal, possibilitando neste caso a reabertura do passado para fins de revisão histórica: "Me misturo no ventre do mato mordendo raízes" (BOPP, 2009, p. 3). Num plano maravilhosos, o retorno ao "ventre do mato" empreendido pela cobra encontra um Brasil gestado na diversidade, irreverente e sincrético. O resgate da própria história é plasmado na história da terra, sempre lançando mão da linguagem inovadora.

O desejo de reconhecer a origem ou linhagem é, por si só, uma marca do clássico no contemporâneo. De toda forma, a paisagem mítica e outros signos da cultura clássica, são trabalhados dentro das correntes da literatura modernista para auxiliar na busca de valores identitários, função que serve a uma necessidade daquele momento histórico-cultural.

Em suma, quer no passado, quer no presente, o mito tem estado em permanente comunhão com as artes em geral e com a literatura em particular. Nos momentos da épica mais pura e nas estéticas mais rebeldes, o artista solicita ao clássico suas inspirações e temas.

\section{Conclusão}

Para existir literariamente, a visão primitiva e primitivista que funda 0 poema fez-se também como metáfora, e é dessa maneira que é preciso analisála. Assim, foi possível observar de que processos se valeu Raul Bopp para a criação do poema, posto que Cobra Norato se projeta, antes de tudo, como imagem.

O poeta recria em Cobra Norato (2009), uma linguagem de grande valor estético onde cada ponto se articula no sentido de reforçar a ideia de trajetória 
pelos caminhos de um mundo arcano, uma viagem onírica que leva à ampliação da consciência. Como pudemos observar anteriormente, isso foi possível porque "a visão mágico-poética que formou a macroestrutura do poema se repete na sua microestrutura, na organização das imagens, na relação entre as palavras" (AVERBUCH, 1985, p. 142).

Dando prosseguimento às análises feitas, entendemos que apesar das adaptações da forma épica e do novo tratamento dado ao tema mítico, é significativa a pervivência do clássico no tracejar de Cobra Norato (2009). A interpretação e o aproveitamento moderno da épica e dos mitos clássicos os tornam tão interessantes quanto os tradicionais. De uma maneira surpreendente e paradoxal, o artista modernista emprega o clássico mesmo na rebeldia, na renovação.

O clássico, seja traduzido, transfigurado ou ambientado, tem constituído sempre fonte perene e inesgotável onde os artistas de todos os calibres têm ido bebericar inspirações. Como verificamos, é assim desde as instâncias grecolatino, às composições inovadoras tocadas pelo folclore popular amazonense. Aliás, o emprego de substâncias clássicas por parte dos literatos e artistas contemporâneos dá ainda mais dignidade à tradição, pois a todo momento se descobre nela um interesse atualizável.

\section{Referências Bibliográficas:}

ANDRADE, Oswald. A utopia Antropofágica. São Paulo: Globo, 2011.

AVERBUCK, Lígia Morrone. Cobra Norato e a Revolução Caraíba. Rio de Janeiro: José Olympio Editora, 1985.

BOPP, Raul. Cobra Norato. Rio de Janeiro: José Olympio, 2009.

. Vida e morte da antropofagia. Rio de Janeiro: Civilização Brasileira, 1977.

. Movimento modernista no Brasil (1922-1928). Rio de Janeiro: Livraria São José, 1966.

BLUMENBERG, Has. Mundo de la via" y tecnificación bajo los aspectos de la fenomenología. Las realidades em que vivimos Trad. Valentino Bozal. Barcelona/Buenos Aires/México: Paidós, 1999. 
Hans. El mito y el concepto de realidad. Trad.Carlota Rubies. Barcelona: Editorial Herder, 2004.

DERRIDA, Jacques. Gramaticologia. São Paulo: Perspectiva, 1973

ÉSQUILO. Oréstia. Rio de Janeiro: Jorge Zahar, 2003.

HEGEL, G. W Friedrich. Estética. Trad. Álvaro Ribeiro, Orlando Vitorino. Lisboa: Guimarães Editora, 1993.

HUCHET, Stéphane. Prefácio: Passos e caminhos de uma teoria da arte. In: DIDIHUBERMAN, Georges. O que vemos, o que nos olha. São Paulo: Editora 34, 2010.

NUÑEZ, Carlinda F. Pate. A mímesis astuciosa: paisagens míticas na literatura brasileira contemporânea. In: SANTOS, Ana Cristina F. Dos, Tereza Virgínia Ribeiro. Tradução e tradição clássica na América Latina. Vol. Belo Horizonte: FALE/UFMG, 2011.

OLIVEIRA, Vera Lúcia de. Poesia, mito e história no Modernismo brasileiro. São Paulo: Editora Unesp, 2002.

PROENÇA, M. Cavalcante. Prefácio. In: BOPP, Raul. Cobra Norato e Outros Poemas. Rio de Janeiro: Civilização Brasileira, 1973.

SANTIAGO, Silviano. A permanência da tradição no discurso do modernismo. Nas malhas da letra. Rio de Janeiro: Rocco, 2002

SZONDI, Peter. Antigüidad clásica y modernidad en la estética de la época de Goethe. In: Poética y filosofia de la história I. Madrid: Visor, 1992.

WARBURG, Aby. Atlas Mnemosyne. Trad. Joaquín Chamorro Mielke. Madri: AKAL, 2010. 